\title{
Creating Books in Communities: A Book Making Program with Families in a Remote Community in Western Australia
}

\author{
Caroline Barratt-Pugh ${ }^{1}$ (D) Yvonne Haig $^{1}$
}

Published online: 9 September 2019

(c) The Author(s) 2019

\begin{abstract}
This article describes the needs analysis, implementation and outcomes of a pilot program aimed at creating books with families in ways that represent their language and culture. Creating Books in Communities is part of Better Beginnings, a state-wide program, developed by the State Library of Western Australia, for children and their families, that aims to develop literacy skills through fostering a love of books and language. Literature about the importance of recognising and valuing home languages and culture in supporting early literacy learning and the impact of family literacy programs is explored to provide a background to the program. The process of Creating Books in Communities is described in detail-it involves collaboration between librarians, early childhood partners, and community based artists working with families to produce a high-quality book. The impact of the program is explored through the voices of all the participants, revealing a number of positive family and community outcomes. We conclude the article by identifying six key factors related to the success of the program, which can be used as guidelines for implementation of the program both nationally and internationally.
\end{abstract}

Keywords Literacy programs $\cdot$ Diverse families $\cdot$ Book making $\cdot$ Community partnerships $\cdot$ Art

\section{Introduction}

Better Beginnings was developed in 2005, for families in Western Australia with a new baby. It provides a 'gift' book, literacy resources and information for mothers about how to support early literacy through stories, songs and rhymes (see https://www.better-beginnings.com.au). Currently, Better Beginnings reaches over 70,000 families each year, who live across an area almost as large as Western Europe, exemplified by social/cultural, economic and geographical diversity, in which over $19 \%$ of families speak a language other than English (Australian Bureau of Statistics 2016). The development of Creating Books in Communities was based on the longitudinal evaluation of Better Beginnings (Barratt-Pugh and Allen 2011).

Caroline Barratt-Pugh

c.barratt_pugh@ecu.edu.au

1 School of Education, Edith Cowan University, 2 Bradford Street, Mt Lawley, WA 6050, Australia

\section{Needs Assessment}

The longitudinal evaluation of Better Beginnings began with 300 parents/carers, 10 librarians, 13 community child health nurses, and two members of the Better Beginnings team, and was undertaken over a period of 4 years. Data analysis revealed a number of positive outcomes for families, librarians, and community child health nurses who delivered the program. However, participants also identified aspects of the program that could be improved. In particular some families were identified as unable to access Better Beginnings. These included hard to reach families living in vulnerable circumstances, Aboriginal families, and culturally and linguistically diverse (CaLD) families. This paper describes the development of Creating Books in Communities which grew from the following three key findings related to CaLD families.

First, the needs of families from culturally and linguistically diverse backgrounds were not being met. Some parents/ carers felt that as they could not speak English well enough to share the Better Beginnings gift book, it was not appropriate to talk about books in their home language. Other parents/carers felt reticent or unsure about interacting with their child in their home language, particularly when using the Better Beginnings resources which were all in English. 
Unfortunately, these perceptions are not unusual; evidence suggests that some parents/carers see their home language as a deficit and disadvantage, believing that this impacts negatively on their child's success at school (Ball 2010). Furthermore, studies have reported that in some culturally and linguistically diverse (CaLD) families, children deny and reject their home language, ultimately leaving them unable to communicate with some family members (Ball 2010; Wong-Fillmore 2000).

In fact, it is very clear from a wealth of research that children from CaLD backgrounds have experiences and knowledge that enhance their ability to learn and use other literacies (Naqvi et al. 2012; Purcell-Gates et al. 2011; Taylor et al. 2008), and which shape their understanding about print before they commence school (Purcell-Gates et al. 2011). Moreover, it is argued that these children's acquisition of new literacy skills can be enriched by building on existing cultural literacy skills. Ball (2010) argued that conserving children's home languages is critical to "equitable access to educational achievement for all" (p. 57). Thus, recognising the centrality of culture and language/s in learning and development. In addition, the significance of children's home language/s and cultural understanding cannot be underestimated in relation to positive social and emotional development and the formation of family and community relationships (Wong-Fillmore 2000).

Second, there was a lack of resources that represented the cultural and linguistic diversity of Australia. The limited number of 'gift' books and library books that represented the linguistic and cultural diversity of families was identified as problematic within the Better Beginnings Program. Parents/carers commented on how much they appreciated the 'gift' book, but how they would also like access to books that included their family background. Librarians were concerned about the lack of diverse books in their children's literature collections, especially in communities that had a relatively high proportion of CaLD families. Research suggests that children's literature has a significant impact on children's social, emotional and intellectual development, particularly in relation to their sense of identity (Kara-Soteriou and Rose 2008; O'Neill 2010). Access to authentic images related to children's cultural and linguistic backgrounds give children a sense of security and belonging (Jones Diaz and Harvey 2002; Morgan 2009). However, sourcing appropriate and accurate literature is challenging (Adam et al. 2017). Although the number of books representing cultural and linguistic diversity is increasing it is still relativity low (Mendoza and Reese 2001). This is particularly worrying as research indicates that parents' own reading behaviours, shared book reading with children, and access to books are all associated with successful transition to school and reading at school as well as positive social, emotional and education outcomes (Sonnenschein and Munsterman 2002; Tilley-Lubbs 2011). In particular, evidence suggests that parent-child book sharing facilitates children's early language and vocabulary development (Farrant and Zubrick 2012). Recent research has identified a connection between shared book reading and the engagement of parts of the brain that support comprehension and mental imagery (Hutton et al. 2015). Gifting children books and providing books in library collections that families can identify with has the potential to increase book sharing, a love of books and early literacy learning, while simultaneously valuing and acknowledging diversity (Barratt-Pugh et al. 2017; Garcia and Hasson 2004).

Third, the Better Beginnings Program needs to be extended to develop a family literacy program that builds on community languages. Several of the parents/carers and librarians argued that a dedicated program for CaLD families would extend the reach of Better Beginnings, support children's homes language/s, and strengthen their connection to their cultural background. While there are many preschool family literacy programs, relatively few are designed for CaLD families. Manza et al. (2010) found that providing appropriate and responsive literacy interventions for CaLD families is a major challenge. In their review of family literacy programs, Carpentieri et al. (2011) argue that "programme developers and researchers should devote greater attention to the cultural validity of initiatives, in order to ensure that they successfully meet the needs of low-income families and ethnically diverse target groups" (p. 17). Again, stressing the importance of cultural and linguistic validity of early interventions and the right of children to use and develop their first language.

While there has been a relative lack of programs for CaLD families, a number of studies have demonstrated the impact of those that are available for CaLD communities involving joint parent-child activities, both priorto-school and in school. KindiLink is a West Australian initiative for Aboriginal families with 3-year-olds. The year-long program incorporates Aboriginal languages and culture as a means of building on and extending parent-child engagement in literacy. Findings from this program suggests that there was an increase in mothers/carers confidence and capacity to support their child and a growing pride in their culture and language/s, while children showed clear development in their home language and English (Barratt-Pugh et al. 2018). Harper et al. (2011) and Rodrigues-Valls (2011) examined joint parent-child literacy programs and described how in both programs mothers were provided with strategies and collaborative activities to improve their children's literacy. Harper et al. (2011) reviewed a 9-week lunchtime program for CaLD families involving mothers and their kindergarten-aged children, while Rodriguez-Valls (2011) report on a 2-year after school Reading Cooperative that sought to foster 
biliteracy. First grade students and their mothers and teachers were involved in reading and analysing bilingual books together. The program brought family members together; allowed exploration of identities; improved children's attitudes about learning English; and encouraged mothers to continue using the strategies at home. Mothers experienced a sense of empowerment at being able to help improve their children's literacy and a sense of pride in the valuing of their first language, while the children progressed on standardised literacy tests. These positive outcomes were attributed to a range of factors such as the contributions of the classroom teachers; the children's cognitive maturity; and the project activities.

Other studies have examined the impact of CaLD programs that were based on telling, recording and publishing family stories. Dworin's (2006) project involved children in a bilingual classroom writing stories about their families in English and Spanish, which were published and shared with families. Dworin's findings suggest that biliteracy may be an important learning tool, enhancing intellectual development and access to various social and cultural resources. Lotherington et al. (2008) report the practice in a linguistically diverse public school in Toronto, Canada, where the teacher encouraged mothers to tell their children stories in their home language, which the children then wrote down in English. As well as supporting the children's English and home language learning, the valuing of mothers' contributions generated a sense of pride in having their cultures and languages acknowledged in a classroom. This, in turn, motivated the children.

In the family literacy program studied by Tilley-Lubbs (2011), the participants were Mexican and Honduran families and the program involved English classes for adults, English tutoring for the children, cultural activities, Spanish classes, as well as an online interactive component for the adults who were mostly women. There were bicultural activities for the children and written follow-up activities for the mothers which focussed on bilingual books. Outcomes included the parents'/caregivers' increased understanding of the importance of reading; their sense of empowerment in helping their children; and their ongoing requests for activities to deepen their children's learning experiences. The children's attitudes towards school and their performance at school also improved.

In summary, research suggests that that family literacy programs that recognise the value and significance of home languages and culture contribute to an increased role for parents/caregivers as their child's first teacher, children's literacy development and children's growing identities within their own cultures (Hirst et al. 2010; Naqvi et al. 2012; Taylor et al. 2008; Timmons et al. 2008).

\section{Planning}

Based on the above three findings from the evaluation of Better Beginnings, Creating Books in Communities was developed to encourage CaLD families to publish their own stories in their own language/s. The model for Creating Books in Communities was informed by the Kids Own Publishing program (see http://kidsownpublishing.com/ for more details). Kids Own Publishing originated in Ireland as a means of publishing books which were meaningful to different communities and families. This model involves an artist, musician or dancer, a local librarian and community members working with families with young children from diverse backgrounds to create and publish a book that documents and celebrates local stories and culture through affordable digital print and on demand technology.

Creating Books in Communities was piloted in seven CaLD communities in Western Australia. This article describes the planning implementation and outcomes of the program in Grevillea, a remote community, located $900 \mathrm{~km}$, north of Perth, WA. Ten percent of the population speak a language other than English, which includes Vietnamese, Mandarin, Italian, Croatian, and Hindi (Australia Bureau of Statistics 2016). The Australian Early Development Census (AEDC) indicated that almost 20\% of children entering pre-primary were "at risk" of poor educational outcomes in language, communication, social and emotional domains (Department of Education and Training 2016).

The local librarian (Nguyen), a designer/publisher and a volunteer from Grevillea, attended the SLWA regional training. The training involved an introduction to book making with families, an explanation of the design of a 'hot dog' book and the stages of the book making process, the roles of the participants, and the publication process and potential cost.

Having completed the training, Nguyen, the librarian, undertook a local needs analysis to determine the support for the program and how to tailor it to the needs of the local community. Nguyen shared the cultural and linguistic background of members of the community and had deep insights into their traditions and aspirations. Having already developed strong relationships with some community members, Nguyen was able to speak to key people in the community, a number of family business owners, and families who attended the local community language classes to gain their interest in developing the program. There was great enthusiasm for the program and Nguyen formed a working group which included a key member of the CaLD community, the artist (a ceramicist), the designer/printer, the library coordinator, and a local 
woman who volunteered to work with program. The working group in consultation with families, decided that all CaLD families with young children would be invited to participate in the program, it would be held at the same venue as the community language classes, once a week for 6 weeks. Funding was gained from the SLWA and the local Shire of Grevillea gave in-kind support.

It was agreed that Nguyen and Daly, the ceramicist with a strong interest in community projects, would lead the program with support from two library assistants, the member of the local community who was on the working group, and support from a member of the SLWA Better Beginnings team. Nguyen approached a member of the working group to invite families with young children to the program. Some 13 family groups with 16 children and their mothers participated. These families shared the same cultural and linguistic background and most worked in the same local industry. There were six boys and ten girls ranging in age from 2 to 12 years at the commencement of the program. Although initially the program was aimed at families with young children, the potential value of including all family members was recognised and the older children were welcomed.

\section{Implementation}

Workshops were held in the library after school for 2 hours once a week, for 6 weeks. The librarian and the artist planned the detail of each workshop content in consultation with the mothers. The theme that guided the workshop sessions and formed the basis of the book was selected by the children and focused on their families and homes. The workshops generally consisted of discussions with guiding questions about an aspect of their family life. Participants discussed, planned, and recorded their ideas through pictures and text, and then a hands-on activity whereby the children expressed their ideas through the medium of clay. The book making process was initiated by demonstrating the 'hot dog' book process. Daly explained:

Each week there had to be a balance between talk and action. There was a lot of talk. But there had to be a balance so the children and mums would be engaged and enjoy the activity. A lot of planning was done. The approach evolved as we reviewed each week and adapted it for the next week.

Comments and ideas expressed by the children during the workshops were recorded by Nguyen and Daly and stored in the relevant child's file along with photos taken of the children's art work. These formed the basis of the book in which the photographs were captioned with their comments or ideas in their home language and English. In week one photographs were taken of all the children, and the topic was about growing and eating food. In workshops two, three, and four, the discussion and artwork focussed on family, friends and homes, and what they like to do and where they like to go in the community. Their art work included representations of family members, their homes, activities the children enjoyed, favourite foods, and their family tree. In workshop five, the families discussed colour and how this could be applied to their clay art pieces. In the final workshop, a draft of the book was shown to the children. They decided on the title and cover design and gave editing advise. One mother commented that she liked the way the "younger and older children worked together and help one another, teach one another" and expressed appreciation for the way "the book was theirs [children's] —adults help but they [children] say what they want." The book was 32 pages long, and included a page about each family with photographs of all the children involved. It was launched by a Shire Councillor. To respond to the high level of demand for copies of the book, an electronic version featuring the children reading the book was developed and made available on the Better Beginnings website. Some of the books published through Creating Books in Communities are available at https://www.better-beginnings .com.au/programs/books-go.

\section{Outcomes}

Evaluation is an essential part of any of family literacy program, involving all participants and stakeholders (Carpentieri et al. 2011). In the case of Creating Books in Communities, the SLWA undertook an independent evaluation which was negotiated with the participants. This included participant and stakeholder perspectives of the implementation process and outcomes of the program. Data collection included two focus groups interviews with 12 mothers, interviews with the adults involved in planning and implementing the program, and observations of the book-making workshops. Copies of photographs of the art work produced in the workshops, taken as part of the book preparation, were also collected. During the seven book making workshops that followed, the research assistant collected further data through observations and informal discussions with the families. An interpreter was involved in the evaluation to support mothers who felt more comfortable speaking in their home language. The analysis of the data was checked with participants to ensure views had been accurately interpreted and the final report was made available to all participants. It was agreed that elements of the data collection method and analysis could be used in future iterations of the program by the participants and stakeholders. Informed consent was obtained from all individual participants included in the evaluation. 


\section{Program Implementation}

\section{Ownership of the Process Led to Engagement in the Program}

The findings show that the participants had a vital role in negotiating, selecting, and driving the theme and design of the book which promoted their ownership of, and engagement with, the program and gave them a 'voice' and an audience for their stories. Involving mothers in the design of the program contributed to ensuring that motivation and attendance were maintained and that the negotiated design of the book met their needs and those of their children. Further, the children's control of the creative process and the book's bilingual approach focussing on their lives within their families and community, led to an awakening interest in their cultural heritage. A sense of shared ownership was also evident in the preparation and involvement of the book launch at the local library, as families and children displayed their art works and talked enthusiastically with guests about the development of the art and the book making process.

\section{Arts-Based Program Led to Multiple Outcomes}

The use of an arts-based program as the common context within which to create a book was perceived by the participants to be very effective and to confer benefits in addition to the production of the book. The mothers, librarian (Nguyen) and ceramist (Daly) noted that the ceramics engaged the children, stimulated talk about ideas that later informed the writing of the text, and provided a means of expression that suited the range of ages involved in the program. In addition, the ceramist suggested that the program provided an opportunity for a community who were "hidden away" to be seen by the wider community. She felt that the art would provide the community with a medium of expression that was more "open and comfortable and open to different interpretations and gives a glimpse into others' lives". These findings were confirmed by the data from the workshop observations, exemplified by the analysis of the planning documents and the written products from the workshops.

\section{Book Design Led to the Extension of Book Making}

A further common feature of the workshop which the participants reported as particularly effective was the use of the 'hot dog' books to illustrate the process of book making. It was simple, relatively inexpensive, and effective, and provided a template for other story telling programs. For example, teachers in local schools adopted the strategy; a library staff member ran a hot dog making program at the
Children's International Arts Festival and the library staff trained local volunteers who then jointly ran a holiday program for children. In addition, the effectiveness of this technique was enhanced by its link to a travelling book cubby, another component of the program which provided children, in addition to those involved directly in the program, with an opportunity to make their own 'hot dog' book illustrated with personal photographs and/or artwork and to 'publish' it through photocopying. The Creating Books in Community Program commissioned three cubbies which continue to be used in libraries and at community events. Copies of the 'hot dog' books produced in the program were added to the collection displayed in these cubbies. Copies were also displayed in the local library, the SLWA, local school libraries, and child care centres and a copy was placed in the Better Beginnings resource pack for families.

\section{Program 'Driver' Led to Coherence and Sustainability of the Program}

The program largely depended on the work of a "key driver" who ensured that it had momentum from its inception to its conclusion. Nguyen, the librarian took on the role of the 'key driver'. She initiated the program, formed a working group, recruited participants and was involved in the facilitation of every aspect. This included ensuring a partnership model formed the basis of the program, involving the working group, the artist, families and the adults supporting the program implementation. This partnership included preparation of the venue and weekly plans, management of the workshops and their documentation, liaison with the designer/ printer, checking the text in both languages for accuracy and correctness and the design of the cover of the book. As the key driver, Nguyen promoted a commitment to the book as a product and bookmaking as a process in all of the participants. In doing so, the group's commitment to the book contributed to high attendance by all participants at the sessions, with no attrition. The partnerships extended beyond the program as the book was launched into the community and made into an e-book and the book making process was extending into the wider community.

\section{Outcomes for Children and Families}

\section{Increase in Engagement with Books}

There was an increase in the frequency and duration of children's interaction with books, particularly by sharing them with their mothers. This was due in part to an increased interest in books, particularly the one created in the program, of both the mothers and the children. The children's developing competence and increased interest in their 
CaLD language was also seen to influence this change. For example, Yue, one of the mothers reported how her young daughter now integrates literacy related activities in both her languages into her play:

Before she play in the cubby in English and draw and write English words. Now she write both (languages) and is more interested. And we read and write together. I show her new [CaLD language] words. She is very keen and she doing much better.

This growing interest and competence led to increased book sharing with mothers and children taking complementary roles.

The mothers indicated that their children initiated more book reading after the program, reporting that their children wanted to read "our" book "all the time", "loved it", and were "very proud" of it. The mothers saw that this was partly due to their strong personal connection to the book as reflected in the summary of a conversation among the mothers in the focus group, reported by the interpreter:

The different thing is, because they were actually involved in it, so it's a lot different, and they reckon, you know, they can do it! They're excited about it, and because it has got [CaLD language] and English, and all the kids' photos in there and what they like, what they draw, family tree of each member of the family.

This increasing interest in books appeared to have an impact on some of the younger children's developing understanding of concepts of print, as they turned the pages, pointed to the illustrations and talked about the pictures with their parent/carer. Ling reported that, "[child's name] got interested in books after the project. He can concentrate more now. He points and names things". Other mothers explained how their children had shown an increasing interest in environmental print, including looking at advertising brochures, magazines and newspapers as well as noticing signs and posters when they were out with their families.

\section{Increase in Access to Books}

The increased interest in reading led to the children having greater access to books. The number of books in the home varied considerably over the group with some mothers reporting as few as five and others over a hundred. However, seven mothers reported that they had bought their children more books since the program, particularly trying to source books in their home language. Additionally, relatives, especially those who lived in the home country, gave the children books in response to their increased interest in reading the CaLD language. In addition, all the families reported joining the local library and subsequent to the program borrowing both English and CaLD language books to read at home.
However, the librarian and mothers commented on how difficult it was to find suitable books in the home language. In addition, 8 months after the publication of the book, it was still being read and talked about, which indicates the ongoing impact it had on children and families, as one of the mothers, Cathy, explained "We still read the book. We gave copies to the relatives and they were very happy". This suggests that the high value the community placed on the book and their strong connection to it were important to sustaining the outcomes of the program.

\section{Changes in Literacy Practices}

The workshop activities and the high-quality book published as a result of them had a considerable influence on the changes in the participants' literacy practices. This may have been because the book creation process emphasised collaboration between children and their mothers and modelled new ways for them to interact in literacy-related activities. The mothers saw the book and the process of making it as useful, particularly because it was a bilingual text that meant they could write and read it together with their children. They could use their complementary skills, with mothers supporting their children to read and write the CaLD language text and the children writing and reading the English version to their mothers. As one mother, Mia, explained:

Because my younger kids can read English and the adults they do not know English; they can read [CaLD language]. We can read different parts and share it. And plus the children can read the [CaLD language]. ...mainly they are learning. And $\mathrm{Ma}$ and $\mathrm{Pa}$ [grandparents], they know some but they don't know very much [English].

In addition, some mothers identified a change in their children's interest in literacy activities leading to an increase in reading and writing their CaLD language and a greater role for their them. Another mother, Ling, reported that "They do more reading and they are beginning to write in [CaLD language]. It helped to encourage them to learn to write; the book in [CaLD language] that they made".

\section{Increase in Mothers' Confidence}

This change in literacy practices was influenced by the mothers' greater confidence in their role as supporters of their children's literacy development. The mothers reported that prior to the program, even though they valued education very highly and wanted to assist and encourage their children, they "did not understand'. In a follow up interview 8 months after the program, the mothers reported how this had changed for them since the program with Yen (a mother 
with a middle primary aged son) expressing her experiences in the following way:

Before he read himself and I can't help him and when I say words he correct me; my English, the way I say; now we read and he tell me English but I correct his [CaLD language name]; the way he say [CaLD language] words. Now we same!

Other mothers reported how they valued their changed role in supporting their children's literacy development in the CaLD language. One of the mothers, Yue, described this as "we explain what some words mean and about the culture. What it means. About things in [the CaLD country]". Daly, the ceramicist noted how "they [children] grew in confidence and pride and so did the mothers involved" and that "they were very happy with the book".

\section{Increase in Children's Interest in and Appreciation of Their Culture and Language}

The creation of a book about their lives written in their home language and English served to indicate to the families that their culture and identity was recognised and valued, an outcome identified in other studies. Further, this strengthened family relationships and stimulated the children's interest in their cultural and linguistic heritage and family stories, an outcome of the program valued by all the participants. This also demonstrated the important role of mothers in supporting the bilingual development of their children to other CaLD families in the broader community. The translator summarised a discussion by some of the mothers about the impact of the program on their children:

The kids found out more and they understood and they learnt more about their culture and..... their background, like other kids as well which they never knew before. .... Our culture is very important to us .... It's good that the kids continue to pass it to others.

One of the mothers, Kate, expressed her pride in this change, explaining that the children saw themselves as "bilingual authors" and her friends were "so surprised about the book". This pride in their book and their growing competence in the CaLD language, increased their children's interest in the language classes they attended. Several of the mothers related how before the program their older children had been reluctant to attend the CaLD language classes saying that they did not need to learn it; saying things like, "I don't need that language now; I' $m$ an Aussie". However, since the program they had been able to move on from the basic skills and write meaningful texts, and this together with their new interest in the language and culture of their community had motivated them to continue the classes. Nguyen (the librarian) and Daly (the ceramicist) also recognised this change and noted it in their interviews as a positive outcome of the program. All involved felt a strong sense of achievement and ownership of the book which motivated reading, and for the older children writing as well.

\section{Outcomes for the Community}

All the participants emphasised the way the program had provided a showcase for the CaLD language, culture, and the contribution the CaLD community made to the district where they lived. Some of the mothers reported that because of the wide distribution and launch of the book, they felt better understood and their contribution to the community better appreciated. They were planning shared cultural events and another book of traditional cultural stories to share with the wider community. Nguyen (the librarian) and the two assistant librarians noted that the program had allowed them to build stronger relationships with the CaLD community they served and encouraged library membership and attendance at the Better Beginnings library activities for families. Nguyen was keen for the program to continue:

I have a big dream. I want .... a series of [CaLD language] books.... I want every kid to be able to speak their mother's language and be proud of it; to be happy about their identify; to see they can be a good Australian citizen as an Australian who speaks two languages. If they are not happy, they cannot be a good citizen.

Daly (the ceramist) noted the opportunity the program provided for the broader community to understand the CaLD community, but claimed that in her view the most important outcome of the program was the change in the children. She described how the older boys were "initially very resistant" to the program and did not want to "acknowledge their cultural identity" but that "these same boys a few weeks in opened up and joined in". She said that "the younger children were very responsive" from the beginning of the program and noted that the arts component gave them a "voice" to "express their ideas in a safe environment" and so was a "special vehicle for communication". The librarian and ceramist described how they had strengthened their relationship and jointly developed other arts-based programs to engage local people in the life of the community, and particularly the library. Finally, the program resulted in the library providing improved services to the CaLD community, developing the library collection to better reflect nature of the local population and creating a new position of Children Services Officer to provide leadership in early childhood language and literacy. 


\section{Where to Next?}

Evidence from the remote community of Grevilea, suggests that the Creating Books in Communities Program had a positive impact on families' and children's perceptions and use of their and home language/s. The children felt great pride in their achievement and continued to make reference to their book some time after the end of the program. The partnership model brought together a service provider, community representative, and an artist to support families, work together to produce sustainable outcomes, and potentially develop long-term collaboration. Although the publication of a bilingual book was the aim of this program in Grevilea, this outcome may be equally achievable through the development of books that represent the community they serve. The aim of supporting children to create books with their families as a means of strengthening their culture, language and literacy, and supporting parents/carers as their child's first teacher, is applicable to all families. In fact, Kids Own Publishing, the model that Creating Books in Communities was based on, connects children with professional artists and publish the work that they create through a range of local, national and international projects (http://kidsownpublishi ng.com). We recognise that not all communities have access to the training, processes and support offered by Kids own Publishing, however the framework provided by Kids Own Publishing is sufficiently flexibility to be adapted to the meet local needs. Based on our evaluation of Creating Books in Communities, we offer six key factors related to the successful planning, implementation and outcomes which may be used as guide to other communities who wish to replicate the process.

\section{Involvement of the Target Community}

Families and children are the driving force behind the program. Gathering information from families about their language and culture and involving them in the decisionmaking processes throughout the program is crucial to its success. This provides families with a sense of ownership, self-determination and motivation as they build trust and confidence in the program providers. It also helps to support recruitment and retention as families feel shared control and responsibility for the program.

\section{Identification of a Partner or Partners}

Partnerships form the foundation of the program. It is important to identify partners that share a common vision and purpose and are willing to commit to cash and in-kind support for components of the program. For example, Kids
Own Publishing in Ireland and Australia have partnered with local governments, national and international not-for-profit organisations, schools and early learning centres, museums, resource centres, state libraries, writers' festivals and universities. There may be more than one partner and although negotiating different roles and responsibilities is complex, time consuming, and often difficult, coordination between agencies increases the likelihood of successful outcomes. Different partners may fulfil different roles, for example by supplying transport for families, space for the program, book-making and art resources, and publishing support.

\section{Engagement of a Local Community Artist}

The artist is at the heart of the program. Art enables children to create stories about their lives through engaging and meaningful activities in collaboration with their parents/carers. The artwork becomes the basis of the book giving children a voice and audience for their stories. Children of all ages can contribute to the book as it reflects their interests, experiences and ideas and makes them available to other children and the wider community. The process of creating the book is deeply collaborative as parents/caregivers work together with the artist and other partners to share ideas about the process and product, ensuring authentic engagement and ownership.

\section{Use of a Simple Book-Making Technique}

The use of the "hotdog" book technique is a relatively simple but effective way to create a book. All participants felt able to contribute to the book and families showed great pride in the end product. The high quality of the final publication ensured the book was seen and used as a valuable resource. In the seven pilot communities, the cost of the publication varied between $\$ 1.85$ and $\$ 8.00$ per book per community. Interestingly, there have been approximately 2425 copies printed of the seven titles produced in the pilot program across Western Australia.

\section{Identifying a Space to Publish and Display Community Created Books}

This can be achieved on a local or global scale as a powerful means of sharing family stories and promoting diversity. For example, during the last 5 years the concept of Creating books in Communities has grown and the SLWA has funded three Book Cubbies-"each an interactive exhibition of books written and/or illustrated by children. Stocked with books created by children and communities within Australia and around the world, the Book Cubby travels throughout metro and regional WA" (https://www. better-beginnings.com.au/program/books-go). In addition, 
Kids Own Publishing have a web site in which books from different projects are featured and SLWA has an interactive website where Creating Books in Communities are displayed. However, displaying and/or selling books in the local library, shop, post office, early childhood settings and/or schools is a good starting place, demonstrating the value of families and children's work.

\section{Evaluation}

As suggested earlier evaluation is an essential part of family literacy programs as a means of identifying the efficacy of the program from multiple perspectives. Evaluation helps program providers to modify and extend elements, provide evidence of successful outcomes to potential funding partners and inform other communities who may be considering a similar program. One of the limitations of this project was the failure to include the voices of the children, this would have been a rich and significant addition to the evaluation. Although the views of the children were mediated through the mothers in future they will be invited to give their perspective of the program.

The last word goes to Nguyen, the librarian, who summed up the potential Creating Books in Communities to be such a powerful program:

The format of the project, its process could be applied to different community groups. It is a great way of writing a story. It can be about anything to share in the family or community. We could self-publish. It's another way to empower a community.... It's a good way to bring the community together. Children love to read books with their own pictures or with someone they know.

All procedures performed in studies involving human participants were in accordance with the ethical standards of the institutional research committee (Edith Cowan University Human Research Committee, number 7823) and the Australian Government National Statement on Ethical Conduct in Human Research (2007-Update 2018).

Acknowledgements The authors would like to acknowledge the families, librarians, community partners, and Better Beginnings team member for sharing their deep insights into the Creating Books in Communities program. Their generosity of time and thoughtfulness is very much appreciated.

Funding This study was funded by the State Library of Western Australia, through the Department of Culture and the Arts, Western Australia.

\section{Compliance with Ethical Standards}

Conflict of interest The authors declare that they have no conflict of interest.

Open Access This article is distributed under the terms of the Creative Commons Attribution 4.0 International License (http://creativeco mmons.org/licenses/by/4.0/), which permits unrestricted use, distribution, and reproduction in any medium, provided you give appropriate credit to the original author(s) and the source, provide a link to the Creative Commons license, and indicate if changes were made.

\section{References}

Adam, H., Barratt-Pugh, C., \& Haig, Y. (2017). Book collections in long day care: Do they reflect racial diversity? Australasian Journal of Early Childhood, 42(2), 88-96. https://doi.org/10.23965/ AJEC.42.2.11.

Australian Bureau of Statistics. (2016). Western Australia: Regional data summary. Retrieved November 13, 2018, from https://quick stats.censusdata.abs.gov.au/census_services/getproduct/censu s/2016/quickstat/5?opendocument.

Ball, J. (2010). Enhancing learning of children from diverse language backgrounds: Mother tongue-based bilingual or multilingual education in the early years. Paper 2010/ED/BAS/ECCE/P1/1 prepared for United Nations Educational, Scientific and Cultural Organisation. Retrieved November 25, 2018, from http://unesd oc.unesco.org/images/0021/002122/212270e.pdf.

Barratt-Pugh, C., \& Allen, N. (2011). Making a difference: Findings from better beginnings a family literacy intervention program. Australian Library Journal, 60(3), 195-204. https://doi. org/10.1080/00049670.2011.10722616.

Barratt-Pugh, C., Barblett, L., Knaus, M., Cooper, T., \& Hill, S. (2018). Evaluation of the KindLink Pilot Initiative in Western Australia. Perth, Edith Cowan University. Retrieved June 13 2019, from https://www.education.wa.edu.au.

Barratt-Pugh. C., Rohl, M., \& Allen, N. (2017). "The first time I've felt included" Inclusive literacy learning in early childhood through school and family literacy programs. In M. Milton (Ed.), Inclusive principles and practices in literacy education. Bingley, UK: Emerald Group Publishing Limited.

Carpentieri, J., Fairfax-Cholmeley, K., Litster, J., \& Vorhaus, J. (2011). Family literacy in Europe: Using parental support initiatives to enhance early literacy development. London: NRDC, Institute of Education.

Department of Education and Training. (2016). Australian Early Development Census National Report 2012. A snapshot of early childhood development in Australia. Canberra, ACT: Commonwealth of Australia, Department of Education and Training. Retrieved November 28, 2018, from www.aedc.gov.au/resources/Depar tmentofEducationandTraining(2016).

Dworin, J. (2006). The family stories project: Using funds of knowledge for writing. The Reading Teacher, 59(6), 510-520. https:// doi.org/10.1598/RT.59.6.1.

Farrant, B. M., \& Zubrick, S. R. (2012). Early vocabulary development: The importance of joint attention and parent-child book reading. First Language, 32(3), 343-364. https://doi.org/10.1177/01427 23711422626.

Garcia, D., \& Hasson, D. (2004). Implementing family literacy programs for linguistically and culturally diverse populations: Key elements to consider. School Community Journal, 14(1), 113-137.

Harper, S., Platt, A., \& Pelletier, J. (2011). Unique effects of a family literacy program on the early reading development of English 
language learners. Early Education and Development, 22(6), 989-1008. https://doi.org/10.1080/10409289.2011.590778.

Hirst, K., Hannon, P., \& Nutbrown, C. (2010). Effects of a preschool bilingual family literacy programme. Journal of Early Childhood Literacy, 10(2), 183-208. https://doi.org/10.1177/1468798410 363838.

Hutton, J. S., Horowitz-Kraus, T., Mendelsohn, A. L., DeWitt, T., \& Holland, S. K. (2015). Home reading environment and brain activation in preschool children listening to stories. Pediatrics, 136(3), 466-478. https://doi.org/10.1542/peds.2015-0359.

Jones Diaz, C. J., \& Harvey, N. (2002). Other words, other worlds: Bilingual identities and literacy. In L. Makin \& C. J. Diaz (Eds.), Literacies in early childhood: Changing views challenging practice (pp. 175-195). Eastgardens, NSW: MacLennon \& Petty.

Kara-Soteriou, J., \& Rose, H. (2008). A bat, a snake, a cockroach, and a fuzzhead: Using children's literature to teach about positive character traits. Young Children, 63(4), 30-36.

Kids Own Publishing. (n.d.). Retrieved November 10, 2018, from http://kidsownpublishing.com/.

Lotherington, H., Holland, M., Sotoudeh, S., \& Zentena, M. (2008). Project-based community language learning: Three narratives of multilingual story-telling in early childhood education. The Canadian Modern Language Review, 65(1), 125-145. https://doi. org $/ 10.3138 / \mathrm{cmlr} .65 .1 .125$.

Manza, P. H., Hughes, C., Barnabas, E., Bracaliello, C., \& GinsburgBlock, M. (2010). A descriptive review and meta-analysis of family-based emergent literacy interventions: To what extent is the research applicable to low-income, ethnic-minority or linguistically-diverse young children? Early Childhood Research Quarterly, 25(4), 409-431. https://doi.org/10.1016/j.ecres q.2010.03.002.

Mendoza, J., \& Reese, D. (2001). Examining multicultural picture books for the early childhood classroom: Possibilities and pitfalls. Early Childhood Research \& Practice, 3(2), 4-21.

Morgan, H. (2009). Gender, racial, and ethnic misrepresentation in children's books: A comparative look. Childhood Education, 85(3), 187-190. https://doi.org/10.1080/00094056.2009.10521 389.

Naqvi, R., McKeough, A., Thorne, K., \& Pfitscher, C. (2012). Dual-language books as an emergent-literacy resource:
Culturally and linguistically responsive teaching and learning. Journal of Early Childhood Literacy, 13(4), 501-528. https://doi. org/10.1177/1468798412442886.

O'Neill, K. (2010). Once upon today: Teaching for social justice with postmodern picture books. Children's Literature in Education, 41(1), 40-51. https://doi.org/10.1007/s10583-009-9097-9.

Purcell-Gates, V., Melzi, G., Najafi, B., \& Orellana, M. (2011). Building literacy instruction from children's sociocultural worlds. Child Development Perspectives, 5(1), 22-27. https://doi.org/10.111 $1 /$ j.1750-8606.2010.00144.x.

Rodriguez-Valls, F. (2011). Coexisting languages: Reading bilingual books with biliterate eyes. Bilingual Research Journal: The Journal of the National Association for Bilingual Education, 34(1), 19-37. https://doi.org/10.1080/15235882.2011.569223.

Sonnenschein, S., \& Munsterman, K. (2002). The influence of homebased reading interactions on 5-year-olds' reading motivations and early literacy development. Early Childhood Research Quarterly, 17(3), 318-337. https://doi.org/10.1016/S0885-2006(02)00167-9.

Taylor, L., Bernhard, J., Garg, S., \& Cummins, J. (2008). Affirming plural belonging: Building on students' family-based cultural and linguistic capital through multiliteracies pedagogy. Journal of Early Childhood Literacy, 8(3), 269-294. https://doi. org/10.1177/1468798408096481.

Tilley-Lubbs, G. (2011). The power is in the partnership: Families as partners in bilingual bicultural family literacy programs. Creative Education, 2(3), 288-291. https://doi.org/10.4236/ce.2011.23039.

Timmons, V., Walton, F., O'Keefe, A. R., \& Wagner, M. (2008). Families learning together: A family literacy program with Mi'kmaw communities in Atlantic Canada. Canadian Journal of Native Education, 31(2), 94-109.

Wong-Fillmore, L. (2000). Loss of family languages: Should educators be concerned? Theory into Practice, 39, 203-210. https://doi. org/10.1207/s15430421tip3904_3.

Publisher's Note Springer Nature remains neutral with regard to jurisdictional claims in published maps and institutional affiliations. 